\title{
Constitución mexicana de 1917 y la arqueología de revoluciones en derecho
}

\author{
Lukasz Czarnecki
}

\begin{abstract}
o
¿Cuáles son las fuentes jurídicas y axiológicas de la Constitución mexicana de 1917? ¿Qué son las revoluciones en derecho al analizar dicha Carta Magna con el especial énfasis para el estudio de las soluciones concretas del ordenamiento actual? Éstas son las preguntas que giran al trono de la reflexión de los impactos de las revoluciones del derecho, comenzando desde la revolución papal del siglo XI, la revolución luterana del siglo XVI, la revolución inglesa del siglo XVII, la revolución norteamericana y la revolución francesa del siglo XVIII. En conclusión, se defiende la tesis de que la actual Constitución de México es un campo fértil de las revoluciones en derecho que impactan las actuales soluciones y los principios entre las cuales destacan la división de los poderes, el amparo para la protección de los derechos del hombre o el sistema presidencialista que rige el régimen actual.
\end{abstract}

Palabras clave: constitutionalismo mexicano, revoluciones, arqueología de derecho

\begin{abstract}
THE MEXICAN CONSTITUTION OF 1917 AND THE ARCHAEOLOGY OF LEGAL REVOLUTION

This article analyses the legal acts and values that had shaped the constitution of Mexico. The current legal system is analised through a perspective of a number of legal revolutions. Those themes are the main references for this essay, which follows legal revolutions from the 11th century's Papal Revolution, through the 16th and 17th centuries' Protestant Revolution and English Revolution, concluding with the American Revolution and the French Revolution of the 18th century. The article proposes that the Mexican constitution was susceptible to ideas from the various legal revolutions, which coexist in Mexican constitution and therefore still influence the current legal system's rules and solutions, such as the separation of powers, or the so-called writ of amparo, human rights system, and presidential system, which lay ground to the current regime.
\end{abstract}

Keywords: Mexican constitutionalism, revolutions, legal archeology

Dr Lukasz Czarnecki - UNAM, Sistema Nacional de Investigadores Nivel 1, CONACYT-México. Email: lukasz@comunidad.unam.mx, https://orcid.org/0000-0002-0424-7188 
En este trabajo se hará la "arqueología" (Krzanowski 1991; Krzanowski 2008) de las revoluciones del derecho para analizar la Constitución mexicana de 1917 con el especial énfasis para el análisis de las soluciones concretas del ordenamiento actual. Esta Carta Magna refleja impactos de las revoluciones del derecho, comenzando desde la revolución papal del siglo XI, la revolución luterana del siglo XVI, la revolución inglesa del siglo XVII, la revolución norteamericana y la revolución francesa del siglo XVIII, como lo muestra la gráfica 1. Sin embargo, lo que nos interesa aquí es el análisis actual y la "arqueología" de las revoluciones es solamente un puente que conecta el pasado con el presente y futuro, de ahí las propuestas de lege ferenda al final.

Se aprecian estas transformaciones en el derecho que tuvieron impacto en la Constitución de México de 1917. El objetivo grosso modo para este ensayo es analizar las revoluciones del derecho y su impacto actual para la Constitución de 1917.

\section{Revolución papal}

La primera revolución que tuvo impacto en el constitucionalismo mexicano fue la Revolución papal, entre 1075 y 1122. El monje Hildebrando en 1073 se convirtió en Papa Gregorio VII, el autor del Dictatus. Con este personaje se dio el nacimiento para el estado moderno absolutista cuyo ejemplo primero fue la Iglesia Católica. La revolución de Gregorio VII no pretendía ser un cambio radical sino la restauración de las libertades pasadas. En este caso se parecía a la otra revolución inglesa del Oliver Cromwell en siglo XVII.

Manuel García-Pelayo distingue dos periodos de la Edad Media: la alta (siglos IX-XIII) y de la baja (siglos XIII-XVI); para el periodo de la alta Edad Media, el teocentrismo se manifiesta en el campo de Derecho, mientras que el periodo de la baja Edad Media, "la idea teocéntrica de la sociedad comienza a ceder paso a la iuscéntrica" donde se destaca: "a) la formación de un Derecho legal; b) el nacimiento de un estamento profesional de juristas (...)” (García-Pelayo 1991: 1094-1095).

Cabe destacar que la cultura jurídica de la Edad Media, especialmente el trabajo de los abogados del derecho romano y canónico dejó huella para el constitucionalismo occidental y también en el constitucionalismo mexicano. Para entender la Constitución mexicana de 1917 hay que considerar el análisis de la eclesiología medieval.

El Papa Gregorio VII fue el autor de la teoría de las "dos espadas" como la forma de interactuar entre el poder terrenal y el eclesiástico. Otro elemento de la estructura política fue la jerarquía: emperador en la parte superior y, debajo de él, clasificados en orden de autoridad descendente, los príncipes, duques, condes y otros gobernantes, el clero, la nobleza y los burgueses.

Cabe destacar la importancia del concepto de la libertad y justicia de Gregorio VII para quien, “[...] libertas realmente significaba lo mismo que potestas y 


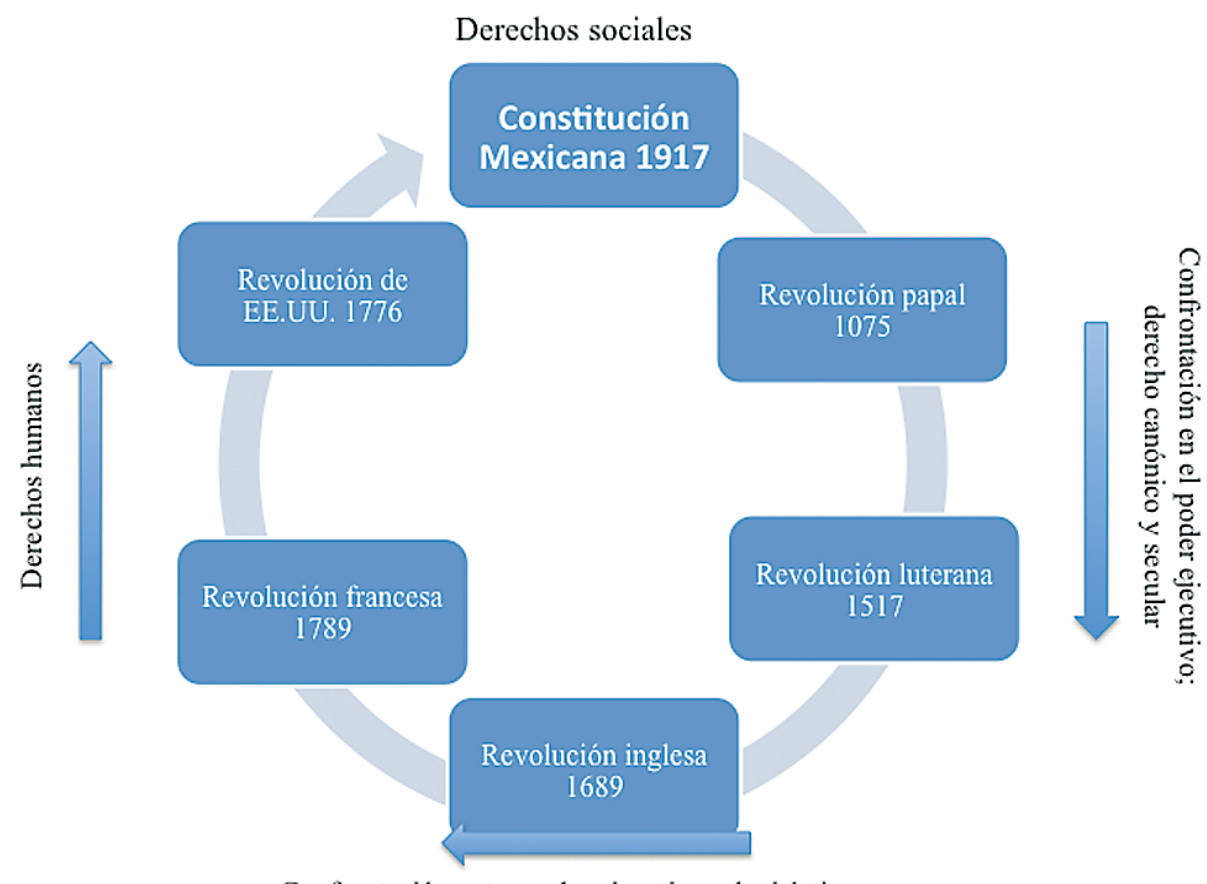

Confrontación entre poder ejecutivo y legislativo

Gráfica 1. Revoluciones occidentales del derecho y su impacto en la Constitución mexicana Fuente: elaboración propia.

honor" (Leyser 1965: 53). La justicia, para Gregorio, "exigía que el servicio a Dios, a la Iglesia, con su cabeza terrenal y sus necesidades, debe tener prioridad sobre la política de pan-y-mantequilla de quienes se hacen disputas feudales" (Idem p. 54). ${ }^{1}$

La teoría canónica de soberanía "dio un modelo para doctrinas del absolutismo real", donde la Iglesia "ejercía la influencia perversa en todos los aspectos de la vida medieval” (Tierney 2008: 4-6). En el siglo XII había una dualidad entre el pasado y presente, comprendido como la dimensión sincrónica y diacrónica.

En el periodo de la Revolución papal hubo un crecimiento de las asociaciones corporativas (universitas), además de las universidades. En el siglo XII, en la Universidad de Bolonga enseñaba el derecho canónico Gratian, el autor de Decretum. Después, gradualmente ocurrió el proceso de la profesionalización de los abogados canónicos y a finales del siglo XIII, "los abogados capacitados parecían haber tomado la iglesia occidental y los clérigos en cada nivel -desde rectores, decanos rurales, canónicos de cátedras, archidiáconos, obispos, arzobispos, cardinales, incluyendo papas- pertenecían a sus rangos".

El derecho canónico estuvo influido por el derecho romano, pero también lo modificó al crear y transformar las reglas jurídicas. Tal es el ejemplo de la doctrina de 
"fuerza y miedo" (vi et metu) en el derecho familiar, donde "los canonistas establecieron la prueba que permitió medir el grado de fuerza suficiente para invalidar el consentimiento" (Reid 2007: 30). Esta prueba fue conocida como la del "hombre constante" (constans vir). Esta norma fue declarada por el Papa Honorio II (1124-1130) para que la prueba se extendiera a las mujeres. El recurso fue utilizado para protegerlas, "especialmente a las chicas jóvenes en sus años de adolescencia, de entrar en matrimonios no deseados" (Idem p. 29). El matrimonio provocado por la fuerza externa podría ser invalidado. Los matrimonios desde el Concilio de Trento, organizado entre 1545 y 1563 , debían tener el lugar in facie Ecclesiae (ante de la Iglesia), en la presencia del sacerdote y dos oficiales testigos. El Concilio que reaccionaba contra los protestantes, reafirmó creencias católicas tradicionales y formuló los ideales de la contrarreforma.

Cabe señalar que el sistema canónico sobre el consentimiento libre fue de alguna manera opuesto al "derecho romano, al derecho natural, al derecho de Dios y derecho de las naciones" (Idem p. 34). Bajo el mismo mecanismo, "los niños fueron reconocidos como posesores del grado de autonomía en la determinación de sus vocaciones" (Idem p. 39).

Desde el derecho romano se distinguían dos facultades de la razón: una facultad de aprehensión, que fue llamada sindéresis, y una facultad de la aplicación, que fue llamada consciencia. Según esta visión, la razón dominaba la conciencia. Este sistema dio legitimización a las monarquías absolutas en siglos posteriores. ${ }^{3}$

Finalmente, la Revolución del siglo XI tuvo impacto en la formulación de los procedimientos judiciales en la Edad Media en adelante. En este periodo apareció la nueva figura del procurador del rey: "El procurador del rey hará lo mismo que los visitantes eclesiásticos en las parroquias, diócesis y comunidades: procurará establecer por inquisitio, por indagación, si hubo crimen, cuál fue y quién lo cometió" (Foucault 1973: 35). ${ }^{4}$ Después de la revolución de 1075, la Iglesia se convirtió en una comunidad visible, corporativa, jerárquica, política y jurídica.

Ahora, la Constitución mexicana de 1917 posee elementos de la revolución papal del siglo XI. Incluye la sombra de la teoría de "dos espadas", donde el poder eclesiástico interactúa con el poder estatal. Existe la jerarquía en el sistema del derecho. Existe también el autoritarismo transcendente relacionado con la figura del presidente de la república. Sin embargo, habría que señalar que la Iglesia fue frenada desde la Constitución de 1857 que introdujo Leyes de Reforma por Benito Juárez. Era tiempo desde la independencia de México de 1810 y su primera Constitución de Apatzingán de 1814 de la confrontación entre los liberales y conservadores sobre las cuestiones dogmáticas y orgánicas de la nueva organización del Estado. La Constitución de 1857 fue un "pacto" entre ambos grupos. Los liberales, por una parte, ganaron en la esfera dogmática y la reducción de la influencia de la Iglesia, de ahí el nacimiento del Estado laico mexicano. Por otra parte, los conservadores ganaron en el mantener la estructura del poder donde el ejecutivo predominaba los otros poderes. Se incorporó el art. 75, después repetido en el 80 de la constitución 
de 1917 sobre el ejecutivo monocrático: „Se deposita el ejercicio del Supremo Poder Ejecutivo de la Unión en un solo individuo, que se denominará Presidente de los Estados Unidos Mexicanos" (DOF 05.02.1917). A pesar del principio de la división de poderes (art. 49), el presidente domina el poder legislativo al ser el iniciador mayor de leyes (art. 71). De la misma manera domina el poder judicial, ya que de acuerdo con el art. 89.XII las facultades y obligaciones del presidente incluyen: "Facilitar al Poder Judicial los auxilios que necesite para el ejercicio expedito de sus funciones".

\section{Revolución luterana}

El segundo impacto es la revolución de principios del siglo XVI. Lutero rechazó la jurisdicción eclesiástica. ${ }^{5}$ La Iglesia no es, según él, la institución que crea las leyes. Al contrario, la Iglesia es el cuerpo místico e invisible de la comunidad de los creyentes, debe servir a cada uno de sus miembros y ayudarlos a cumplir con las enseñanzas de Biblia. Cada uno responde individualmente ante de Dios. La misión de la Iglesia es acompañar a las personas en este camino del cumplimiento de la palabra de Dios. Por eso, Lutero criticaba los abusos del clero, ya que vendían indulgencias y buscaban el poder conforme a la teoría de las "dos espadas". En enero 1521 el papa excomulgó a Lutero considerándolo un herético. El Rey Carlos V en el Edicto de Worms lo declaró "el diablo en el habito de un monje". Lutero rompió sus votos monásticos en 1525 y se casó con la monja Catalina von Bora.

Para Lutero, la autoridad secular política, los príncipes y consejeros, el magistrado y gobernantes deben tomar responsabilidades para la elaboración de las leyes que previamente estuvieron en la disposición la Iglesia católica romana. De ahí, la teoría de los "dos reinos" que son separados y tratan los asuntos distintos: la ley terrenal en la disposición de la autoridad secular política y la ley no terrenal que se ocupa del cumplimiento de la palabra de Dios.

La idea principal de la Revolución de 1517 estriba en que la Iglesia debía ser una comunidad puramente espiritual que forma parte de la esfera celeste de la paz, la alegría, la gracia, la salvación y la gloria de Dios. De ahí, el nuevo modo de sistematización de la ley y los nuevos principios de derecho constitucional. La Iglesia está regida por la ley cuya competencia exclusiva reside en el príncipe y sus ministros.

Para Lutero habría que "reemplazar la visible, legal, jerárquica Iglesia Católica Romana con una invisible, igualitaria asociación de creyentes que vivirían sólo por la fe" (Berman 2003: 63). Se introdujo la jurisdicción sobre los laicos en los asuntos de "familia, delitos morales, educación, ayuda a los pobres, y otros campos. Se introdujo el divorcio por motivos de adulterio o abandono. Herejía, blasfemia, y delitos sexuales se hicieron los crímenes de derecho secular. Leyes seculares se promulgaron sobre la vagancia, la mendicidad, la respetabilidad, suntuosidad del vestido, y similares" (Berman 2003: 64). 
Otro campo de acción del Estado es la educación. A partir de la revolución luterana, se optó por el control laico de la educación. El impacto de esta visión se aprecia en el Artículo 3 de la Constitución de México. Las escuelas y bibliotecas públicas fueron instituidas para reemplazar escuelas católicas y las universidades se colocaron como autoridades. Se subrayan los principios del servicio civil y la responsabilidad pública. Fueron los fundamentos para establecer un monarca constitucional en lugar de un monarca absoluto; se tomaba en cuenta "el estado de leyes" (Rechtsstaat) como única fuente de la "espada" de legitimización del poder. En fin, la revolución protestante tuvo impacto en el concepto de la república y el estado laico que, con la revolución luterana, crece en el poder. El concepto del gobernante laico de Niccolo Machiavelli (1469-1527) y de Jean Bodin (1530-1596) se convierte en las cortes como el único gobernante terrenal absoluto.

Para la autoridad eclesiástica, según Lutero, "se supone que la ley debe inducir a la gente a evitar el mal, para que cooperen, y para servir a la comunidad" (Berman 2003: 44). El perdón de los pecados sólo puede concederse a través de una confrontación directa entre el pecador arrepentido y Dios, por gracia divina, sin reglas ni procedimientos. La razón es subordinada a la conciencia.

Ahora la revolución luterana se ve reflejada en la Constitución mexicana de 1917 con la total división entre Estado y la Iglesia. Dos visiones opuestas, contradictorias entre el poder terrenal y divino, se reflejan en el concepto de la educación laica, uno de los principios más discutidos durante el constituyente de 1916-1917. Venustiano Carranza, el jefe de Ejercito Constitucionalista solo una vez participó en las sesiones, justo cuando se discutió el art. 3 de la Constitución: "será laica y por completo ajena a cualquier doctrina religiosa". La Constitución de 1917 introdujo el principio de la laicidad y fue en muchos aspectos en contra de la Iglesia católica, sobre todo, durante la guerra cristera de 1926 a 1929 se aprecia la confrontación y las tensiones fuertes entre la autoridad eclesiástica y secular.

Laicidad también impactó en el derecho familiar donde habría que mencionar dos aspectos relevantes: introducción el divorcio incausado y los matrimonios del mismo sexo. Según la jurisprudencia de la Corte Suprema en 2015 se adopta la definición de "la familia como realidad social, es decir, todas las formas y manifestaciones de familia que existen en la sociedad, entre las que se encuentran las homoparentales conformadas por padres del mismo sexo con hijos (biológicos o adoptivos) o sin ellos". ${ }^{6}$ Además, la definición legal del matrimonio que contenga la procreación como finalidad de éste, vulnera los principios de igualdad y no discriminación.

\section{Revolución inglesa}

Esta revolución es la segunda revolución protestante, después de la luterana. Se fundamentaba en la crítica de la monarquía absoluta del siglo XVII, en contra 
de la visión de Bodin y Macchiavello. Se denomina la revolución calvinista, ya que se basa en las ideas de Juan Calvino (1509-1564).

Antes de la revolución luterana e inglesa, los canonistas y romanistas, los teólogos y filósofos, formaban una comunidad. Sin embargo, con la reforma en el continente europea y creciente división de Inglaterra y Roma, a partir del rey Enrique VIII, empezó la diferenciación en los sistemas jurídicos.

En Inglaterra, Richar Hooker, anglicano teólogo y filósofo político publicó en 1590 la obra Sobre los derechos la política eclesiástica (Of The Laws of Ecclesiastical Polity). Hablaba sobre la supremacía de la Iglesia Anglicana en contra de los puritanos y la Iglesia católica. Para Hooker, el derecho "fue fundado en la razón, en la moralidad y en la sociabilidad natural del hombre [...]. Pero él también considero que el derecho es fundado en la voluntad política y en la corrupción de la naturaleza humana que, en aras de la sociabilidad misma, se somete a los comandos de la autoridad política" (Berman 2003: 223).

La jurisprudencia inglesa tiene que ver también con los cambios en el pensamiento científico del siglo XVII. ${ }^{7}$ Sin embargo, los científicos y filósofos trabajaban también para justificar la monarquía absoluta. En Inglaterra de la primera mitad del siglo XVII destacaba Francis Bacon (1561-1626), el filósofo, abogado y el ministro de justicia en la corte del rey Jacobo I (1603-1625) que aplicaba el método empírico de la inducción y defendía la monarquía absoluta, un poder que emerge naturalmente. De ahí se establecen las leyes.

La doctrina moderna de los precedentes (common law) se basaba en esta teoría del conocimiento científico, como lo planteaban en el siglo XVII el químico Robert Boyle (1627-1691) o físico Isaac Newton (1642-1727). La doctrina de precedentes decía que las decisiones judiciales son la fuente de autoridad del derecho. La importancia del conocimiento científico se trasladó a la experiencia, a la verificación y a la observación empírica. En el siglo XVIII fue David Hume (1711-1776) quien consideraba que el conocimiento viene de las experiencias para probar la verdad. También en este sentido se manifestaba la teoría del conocimiento de John Lock (1632-1704).

La Revolución inglesa puede ser concebida también como conservadora, es una reminiscencia del conservadurismo de otras revoluciones. En el siglo XVI, los pastores y los príncipes luteranos trataron de restaurar la autoridad de la Biblia. En los siglos XI y XII, el Papa Gregorio VII invocó la autoridad de los obispos y los consejos de la Iglesia ante del creciente poder del Imperio Carolingio para justificar su lucha por la libertad de la misma. El mito de un retorno era también parte de la ideología de la Revolución francesa.

Existieron diferentes fases de la Revolución inglesa, que duraron de 1640 a 1689. La primera fase fue la guerra civil en contra del monarca, de 1642 a 1649, que se acaba con la decapitación del rey Carlos I el 30 de enero de 1649, la primera destitución del rey por decapitación en la historia moderna. Después, periodo de 
Oliver Cromwell (1649-1660), la restauración (1660-1688), y, finalmente, la Revolución gloriosa de 1688-1689.

Cabe destacar la importancia para esta revolución la introducción del derecho para peticiones, el cual comenzó en la práctica las ideas modernas de la esfera pública. El derecho a la petición en el siglo XVII consistía en un manuscrito impreso que contenía "quejas y solicitudes de carácter público y privado, de los individuos y de las agrupaciones" (Zaret 1996: 1507). Antes de la Revolución inglesa, la comunicación política era muy limitada. El parlamento de 1640 comenzó a utilizar las peticiones y de ahí se puede hacer consideraciones sobre los principios de la opinión pública: "estos desarrollos comunicativos produjeron el fundamento liberaldemocrático - por ejemplo, la importancia de consenso, debate público y la razón de la autoridad en política [...]" (Ide, p. 1508).

En la obra póstuma de Thomas Hobbes de 1681, titulada Un Diálogo entre un filósofo y un estudiante de leyes comunes de Inglaterra, el Filósofo destaca que "la Razón es la Vida del Derecho"; "No es la Sabiduría, pero la Autoridad que crea el Derecho. [...] nadie puede hacer el Derecho, pero sí el Poder Legislativo" (Hobbes 1997: 55). El derecho ya no proviene de un ente supremo como lo fue en la Edad Media después de la revolución papal o del monarca. Desde la revolución en la Inglaterra del siglo XVII, el parlamento, como el poder legislativo, es la fuente del derecho. El derecho común (common law) se convirtió en el derecho constitucional de Inglaterra y después en las colonias norteamericanas.

Los principios de derecho common law, establecidos en el siglo XVII en Inglaterra estribaron en: "1) el establecimiento de la independencia del jurado como el órgano de investigación tanto de los hechos como del derecho, 2) el establecimiento de los derechos substanciales y procedurales de las personas acusadas en los procesos penales, 3) la introducción del sistema de prueba de adversario, y 4) el desarrollo de los nuevos criterios para prueba de culpabilidad en los casos del derecho penal y responsabilidad en los casos civiles" (Berman 2003: 285-286).

En lo que se refiere al punto primero, se consideraba que basarse en el cuerpo colectivo de doce personas anónimas que representan la comunidad es más confiable que el juicio de un juez. Además, por primera vez el acusado se convirtió en sujeto de derechos lo que se relacionaba con la independencia del jurado. Esos cambios se relacionaban con la introducción del "sistema adversario" en lugar del "sistema inquisitorio". Este último estribó en hacer la investigación desde el mando de la corte. El sistema adversario fue la examinación donde primero se formulaba la acusación por el procurador (ministerio), después se presentaba ante la corte. La acusación fue limitada a la evidencia presentada en la acusación. La corte interroga al acusado y después a los testigos. El juicio fue la investigación judicial. Mientras, en el sistema adversario, la presentación de las evidencias fue hecha por el ministerio y la provisión de defensa por la corte. Esto se relacionaba con la introducción de los nuevos criterios de prueba de culpa. Primero es la duda, el grado de probabili- 
dad y, finalmente, la presunción de inocencia. La Revolución inglesa del siglo XVII tenía el mito del retorno a las épocas anteriores "de oro" y restablecer el status quo. En este sentido fue conservadora. También fue fundamental para la transición de la economía feudal hacia la capitalista. La fuente del derecho no es la monarquía absoluta, sino el parlamento.

En lo que se refiere a la Constitución mexicana de 1917 se claramente encuentra las sombras del del derecho común, de los precedentes. Los jueces deberán tener el papel más activo en la protección de los derechos contra la autoridad. Tal es el caso del amparo, por primera vez introducido a la constitución de Yucatán de 1841. Hubo las transformaciones de esta medida para alcanzar el mayor nivel de aplicación de garantías contra la violación de los derechos. A esto se refiere la Nueva Ley de Amparo (DOF 02.03.2013) que por primera vez implemento la responsabilidad de las autoridades por omisiones. ${ }^{8}$ Además, en los artículos 14 y 16 se introducen los principios del debido proceso, principios lex retro non agit y principio de oralidad, donde se garantiza el derecho a la defensa.

\section{Revolución francesa}

Fue concebida como la revolución deísta. Se rechazaba la existencia de Dios, pero se creía que el universo fue creado por él y cada ser humano tiene algunas facultades divinas. Otra vez la contradicción. Cada ser humano nace libre e igual y busca la sabiduría y la felicidad. De ahí, las ideas que son el producto del catolicismo y el protestantismo. Compartieron la misma idea de que Dios creó al hombre con su dignidad y la razón como el conducto de la ley y su transformación.

La diferencia principal entre otras revoluciones fue que en la Revolución francesa se basaron en principios de democracia y derechos del hombre y del ciudadano. El documento fundamental, desde entonces para todos los sistemas jurídicos, fue la Declaración de los Derechos del Hombre y del Ciudadano de 1789. En el punto XVI la Declaración subraya que "una sociedad en la que la garantía de los derechos no está asegurada, ni la separación de poderes determinada, no tiene Constitución". Se aprecia la importancia del reconocimiento de los derechos y la división de los poderes como fundamento para el constitucionalismo mexicano, incluido la Constitución de 1917.

Sin embargo, en palabras de Hannah Arendt, "la posición asumida por Sieyès respecto a la nación, esto es, " que sería ridículo suponer que la nación está limitada por las formalidades o por la constitución a las que la propia nación ha sometido a sus mandatarios ", es igualmente aplicable al principio absoluto, el cual, como la nación de Sieyès, tenía que « ser el origen de toda legalidad », el « fontanar de la justicia », por lo que no podía estar sometido a ninguna ley positiva" (Arendt 2014: 262). Para Arendt, en el Constitutio Libertatis se encuentra el poder especifico que es el nivel más alto de poder comunicativo, el componente del que carece el constitucionalismo francés. 
Además de la crítica de Arendt, Aimé Césaire analiza los límites de la Revolución francesa al referirse al problema colonial de Santo Domingo, "la verdad es que todo el orden napoleónico - un orden burgués - postulaba el restablecimiento de la esclavitud en las islas azucareras; se trata aquí, no tanto de influencias personales o circunstanciales como, y de modo más profundo, de la lógica de un sistema" (Césaire 1967: 345). Las tropas dirigidas por Toussaint Louverture, gobernador de Santo Domingo fueron en contra del régimen usurpador. Los franceses bajaron la bandera de los derechos del hombre y ciudadano y querían en realidad despojar de la libertad del pueblo de la isla azucarera. En las palabras de Louverture, "desconfiad de los blancos, os traicionarán si pueden hacerlo. Su muy manifiesto deseo es el retorno a la esclavitud" (Césaire 1967: 359).

La Revolución francesa trajo las ilusiones de la libertad, fraternidad e igualdad. La Revolución comprobó "que la libertad es indivisible, que no se podía conceder la libertad política o económica a los plantadores blancos y mantener a los mulatos bajo la férula; que no se podía reconocer la igualdad civil a los hombres de color libres y al mismo tiempo mantener a los negros en la ergástula; en una palabra que para liberar a una de las clases de la sociedad colonial había que liberarlas a todas y que para liberarlas había que liberar a Santo Domingo mismo; lo cual le pareció al poder, contrario a los intereses de Francia" (Césaire 1967: 415).

Es cierto que le Revolución francesa en el primer instante buscaba la abolición del sistema opresivo de la explotación y el poder autoritario ejercido por el monarca. Sin embargo, como analiza Césaire, la Revolución buscaba mantener el estatus quo del anicien régime.

Cabe destacar que en lo que se refiere a las leyes, éstas se basaban en la filosofía de racionalización, individualismo y utilitarismo. En el Code civil de 1804, se estableció el principio de la protección de la propiedad privada y los contratos. En el derecho criminal, se estableció el principio de la inocencia y el principio de la no-retroactividad. Los actos criminales deberían ser sancionados, no porque fueran moralmente malas, en comparación con la Revolución luterana en derecho, o porque violaron los estándares tradicionales de la comunidad, según el concepto del derecho common law en la Revolución inglés, sino que, basándose en la Razón, dañan la sociedad y el castigo es indispensable para prevenir a los otros.

La Constitución mexicana de 1917 es un ejemplo moderno de la aplicación de la herencia de la Declaración de los Derechos del Hombre y Ciudadano de 1789 que en el punto 16 estipulaba que la Nación carece la Constitución que no implementa el principio de división de poderes y no garantiza los derechos. Así la Constitución mexicana presenta el más avance en la protección de los derechos sociales, derecho a la educación (art. 3), trabajo digno (art. 123), la salud (art. 4), entre otros. Sin embargo, aparecen las contradicciones entre la esfera dogmática y organización del poder. La "Nación", aunque en el centro de atención, es una figura efímera del gobernante, representante de populus, un ejecutivo cuyo poder es absoluto. Monocratizmo del poder ejecutivo sigue impactando el tiempo actual. 


\section{Revolución norteamericana}

Thomas Jefferson, el principal autor de la Declaración de la Independencia y James Madison, el principal arquitecto de la Constitución de los Estados Unidos, venían de las familias terratenientes que producían tabaco: "Jefferson nació y vivió en Monticello, a 5000 acres de plantación afuera de Charlottesville; Madison fue el maestro de la plantación de Montpelier, 25 millas al norte de Charlottesville" (Cohen 2016: 18).

La Declaración de la Independencia se basaba en las "verdades" que son "evidentes": "que todos los hombres son creados iguales". Desatacaba "la nueva idea americana del poder" (Arendt 2014: 271). Lo que fue radicalmente nuevo en la visión del derecho, diferente de la Revolución francesa e inglesa se fundamentaba en: 1) el federalismo, 2) el continentalismo, i.e. la dimensión de la expansión continental, ilimitada movilidad de la gente y la absorción de los inmigrantes y, 3) el control jurisdiccional de la legislación a través de judicial review (Berman 2003: 16). Lo que la Revolución inglesa aportó significativamente para el sistema del derecho, es decir la independencia del sistema common law, en su versión norteamericana se convirtió en el principio más avanzado en el "orden normativo universal" y fue "decisivo para el mundo moderno" (Parsons 1964: 353).

Arendt subrayó que, al contrario de la Revolución francesa, "en América se elaboraron con la intensión expresa y constante de impedir, en la medida de lo humanamente posible, que los procedimientos de las decisiones mayoritarias degenerasen en el «despotismo electivo» del gobierno de la mayoría" (Arendt 2014: 267).

El padre de la prosperidad económica norteamericana fue Alexander Hamilton, quien fue nombrado en 1789 el primero ministro de la hacienda. El objetivo de las políticas de Hamilton, considerado "al estilo de Macchiavello" (Walling 1995: 419), fue establecer la estabilidad monetaria y la creación del banco central. El desarrollo de los Estados Unidos de América se basaba en las ideas de Hamilton, quien propugnaba "el proteccionismo y la posición fuerte del gobierno nacionalista" (Makki 2004: 152).

Hannah Arendt no observa las contradicciones en la Revolución norteamericana, sino los elementos subyacentes donde "la acción había conducido a la formación del poder" (Arendt 2014: 287), lo que ocurrió en las corporaciones autónomas antes de las guerras de independencia. De ahí para Arendt, "el asunto principal de la Revolución americana [...], resultó ser el establecimiento y fundación de la autoridad, no del poder" (Arendt 2014: 293). ${ }^{9}$

Las contradicciones entre la idea de potestas in populo, expresada en la Constitución y la ausencia del poder de facto se encuentran como puntos cruciales en la Constitución mexicana de 1917. Por un lado, es el mayor avance en los derechos sociales de su tiempo y por el otro, ausencia de éstos de facto.

Además, habría que destacar que la sombra del vecino del norte tiene impacto en la aplicación de la Constitución mexicana. No se refiere a la imitación de 
las provisiones legales, sino de huir de la cualquier imitación posible. Tal es el ejemplo de la figura del veto del presidente (art. 72B). De iure está presente como una imitación del sistema norteamericano, pero de facto no tiene ninguna relevancia en la praxis constitucional. Hasta 1997 jamás fue aplicado cuando gobernaba el hegemónico Partido Revolucionario Institucional, después durante V. Fox (2001-2006), 16 veces y F. Calderon (2007-2012), 8, mientras E. Peña Nieto (2013-2018) nunca ya que se firmó el Pacto por México garantizando el consenso entre PAN, PRI y PRD.

\section{Revolución mexicana}

En 1907, el periodista estadounidense James Creelman llegó a México para hacer una entrevista con el presidente Porfirio Díaz. En 1904, el presidente Porfirio Diaz fue reelegido por séptima vez. Durante la entrevista se confirmó los principios de la democracia, el respeto a las elecciones y no su relección en 1910. A pesar de esta declaración Don Porfirio se postuló y en 1910 ganó las elecciones; así este hecho fue un punto de comienzo directo de la revolución. El iniciador del espíritu revolucionario fue Francisco I. Madero, quien anunció un documento titulado "Plan de San Luis Potosî". Los mensajes claves incluidos en este documento incluían el postulado: "no a la reelección" y "sufragio efectivo!". En el primer momento de la revolución se trata de una lucha por la libertad de la democracia representativa. Según Lorenzo Meyer, al comienzo de los acontecimientos de 1910 años, es difícil hablar en este caso de un componente "revolucionario" (Meyer 1982: 147).

El 28 de noviembre de 1911 Francisco Zapata se fue contra Madero en el documento denominado "Plan de Ayala". Zapata en este documento acusó a Madero de la omisión de la cuestión campesinos y los asuntos de la propiedad de la tierra. Estalló la guerra civil. Primo de Porfirio Diaz, Félix Diaz y Bernardo Reyes trataron de llegar al poder. Luego el general Huerta traicionó a Madero quien fue asesinado, junto con el vicepresidente José Pino Suarez el 22 de febrero de 1913. Victoriano Huerta se convirtió en un nuevo líder de la revolución. En ese momento, el presidente de Estados Unidos, Woodrow Willson, no reconoció el gobierno de Huerta, quien disolvió el Congreso y ordenó una nueva elección.

El 30 de marzo de 1913 en el estado de Coahuila se firmó el "Plan de Guadalupe" por Venustiano Carranza, que se opuso a la dictadura de Huerta. En el art. 6. de este documento se postuló el principio de la legalidad constitucional. En este momento, además de Zapata, también Francisco Villa llevaba luchas separatistas en el Norte. Los aliados de Carranza ganaron a los huertistas y otros movimientos. Uno de los primeros resultados fue la organización de la convocatoria de una asamblea constituyente, es decir, convocar a los representantes de todos los estados para deliberar las enmiendas a la Constitución de 1857.

En febrero de 1917 fue promulgada la nueva Constitución, que postuló la separación de poderes, además de una serie de derechos sociales en particular. La 
Constitución institucionalizó la reforma agraria y la reforma de propiedad de la tierra, abogó por la introducción de la legislación laboral y los derechos de los trabajadores. Por otra parte, en cuanto a la educación, se redujo el papel de la Iglesia Católica.

\section{Conclusiones}

En este ensayo se hizo la "arqueología" de las ideas de la Carta Magna de México donde se observó impactos de las revoluciones occidentales en derechos. En el siglo XI y XII, el Papa Gregorio VII se basó en la autoridad de los obispos y de los Consejos de la Iglesia contra el creciente poder del Imperio carolingio para justificar su poder. En el siglo XVI, Martin Lutero trató de restaurar la autoridad de la Biblia. La Revolución inglésa también se puede considerar como conservador en el sentido que estableció el ancien régime. El mito de una vuelta al statu quo era también parte de la ideología de la Revolución Francesa. En el caso de México, estas contradicciones se encuentran en la Carta Magna. Además, la constitución mexicana es una especie de patchwork, un mosaico en la vasija cuyo sentido puede interpretar solo un arqueólogo. Ahí hay contradicciones entre los liberales y conservadores entorno a la cuestión dogmática y la organización del poder. La "arqueología" sui generis de la Constitución mexicana permitió comprender que ésta a pesar de ser la más avanzada en su tiempo, está llena de las contradicciones profundas aun existentes.

\section{Notas}

1 Traducido del original: “[...] demanded that service to God, the Church, its earthly head and their needs should take precedence over the bread-and-butter politics of who whom, of feuding and princely land-hunger".

2 Brundage, James A. (1994), “The Rise of the Professional Jurist in the Thirteenth Century”, en Syracuse Journal of International Law and Commerce, 20 (185): 1.

3 Para los escolásticos, la razón fue considerada una facultad cognitiva o intelectual superior de la conciencia, la cual fue una habilidad práctica o aplicativa (Berman, 2003: 75). Se recurría a Platón y Aristóteles, estoicismo y teólogos. La legitimización del derecho canónico emanaba de los escritos de Tomás de Aquino (1225-1274) y su Summa Theologiae, entre otras, Francisco de Vitoria (1483-1546), Francisco Suárez (1548-1617), entre más distinguidos.

4 El sistema inquisitorio tiene que ver con los impactos del poder de la Iglesia: "la indagación tuvo un doble origen, origen administrativo ligado al surgimiento del Estado en la época carolingia y origen religioso, eclesiástico, que está presente durante toda la Edad Media. Este procedimiento de indagación fue utilizado por el procurador del rey — la justicia monárquica naciente - para desempeñar la función del delito flagrante" (Ídem).

5 Martin Lutero, profesor de teología en Universidad de Wittenberga, de 34 años, dejó 95 tesis en 1517 en la iglesia de la ciudad. En décadas anteriores hubo tensiones entre la autoridad eclesiástica y secular, sin embargo, dichas tensiones conformaban la unión. Los principales representantes de esta revolución son, además de Martin Lutero, Philip Melanchthon y Johann Oldendorp. Lutero sustituyó a la teoría gregoriana de "dos espadas", en la que los poderes espirituales y seculares, la Iglesia y el Estado, interactúan entre sí, con una teoría nueva de "dos reinos". La Iglesia, enseñaba Lutero, pertenece al reino celestial de la fe; que se rige por el Evangelio. El reino de la tierra, el reino de "este mundo", es el reino del pecado y de la muerte y se rige por la ley del Estado (Berman, 
2003: 40). Esta revolución se fundamentaba en el rechazo de la dialéctica de reconciliación de los puntos opuestos: el espiritual y secular.

6 SCJN de 11 de diciembre de 2015, Tesis: 1a./J. 85/2015 (10a).

7 Dos radicales transformaciones ocurrieron en este siglo: la obra de Galileo Galilei (1564-1642) y la de René Descartes (1592-1650). Galilei fue escéptico sobre la visión de Aristóteles en cuanto al universo. Él utilizó los métodos tanto de la deducción, aplicando la teoría, como de la inducción, a partir de la experiencia, en la investigación y probar la hipótesis. El universo ya no está hecho de la materia y movimiento, sino que hay que descubrirlo. Galileo probó de manera deductiva la teoría de Copérnico De revolutinibus orbium celestium. De la misma manera, Descartes utilizaba los métodos matemáticos. Descartes introdujo las ideas sobre la interdisciplina: "todas las disciplinas están tan interconectados que es mucho más fácil estudiarlas todas juntas que aislar una de todas las demás" (Descartes, 1952: 1).

8 Art. 1o. El juicio de amparo tiene por objeto resolver toda controversia que se suscite: I. Por normas generales, actos u omisiones de autoridad que violen los derechos humanos reconocidos y las garantías otorgadas para su protección por la Constitución Política de los Estados Unidos Mexicanos, así como por los tratados internacionales de los que el Estado Mexicano sea parte; II. Por normas generales, actos u omisiones de la autoridad federal que vulneren o restrinjan la soberanía de los Estados o la esfera de competencias del Distrito Federal, siempre y cuando se violen los derechos humanos reconocidos y las garantías otorgadas para su protección por la Constitución Política de los Estados Unidos Mexicanos; y

III. Por normas generales, actos u omisiones de las autoridades de los Estados o del Distrito Federal, que invadan la esfera de competencia de la autoridad federal, siempre y cuando se violen los derechos humanos reconocidos y las garantías otorgadas por la Constitución Política de los Estados Unidos Mexicanos. El amparo protege a las personas frente a normas generales, actos u omisiones por parte de los poderes públicos o de particulares en los casos señalados en la presente Ley.

(Nueva Ley de Amparo, DOF 02.03.2013

9 Sin embargo, potestas in populo residió solamente en la población sui generis, ya que más de un siglo y después de la guerra civil, todavía la segregación fue la política oficial del estado, al eliminar a la gente mentalmente débil, "en 1904, 17.3 personas mentalmente débiles [feebleminded] fueron institucionalizadas por cada 100,000 personas. Hasta 1921, el número se triplicó hasta 46.7” (Cohen, 2016: 25). Los hombres más ilustres, autores de la Declaración y la Constitución, provenían de Virginia, el estado donde "esterilizaron con la fuerza por lo menos 7450 personas 'impropias' entre 1927 y 1979” (Cohen, 2016: 1).

\section{Referencias bibliográficas:}

Arendt, Hannah

2014 [1963] Sobre la revolución, Madrid: Alianza editorial.

Berman, Harold J.

2003 Law and Revolution, II: The Impact of the Protestant Reformations on the Western Legal Tradition, Cambridge, Massachusetts, London: Harvard University Press.

Césaire, Aimé

Toussaint Louverture. La Revolución francesa y el problema colonial, La Habana: Instituto del Libro.

Cohen, Adam

2016 Imbeciles: The Supreme Court, American Eugenics, and the Sterilization of Carrie Buck, New York: Penguin Rndom House LLC, p. 18. 
Descartes, René

1952 Rules for the Direction of the Mind, en Great Books of the Western World, vol. 31, Chicago, p. 1.

Foucault, Michel

1973 La verdad y las formas jurídicas, Conferencias pronunciadas en Rio de Janeiro entre 21 y 25 de mayo de 1973, p. 35.

García-Pelayo, Manuel

1991 Obras completes II, Madrid: Centro de Estudios Constitucionales, pp. 1094-1095.

Hobbes, Thomas

1997 [1681] A Dialogue Between A Philosopher and A Student of Common Laws of England, Chicago and London: The University of Chicago Press.

Krzanowski, Andrzej

1991 Chancay: ¿una cultura desconocida?, w Estudios sobre la cultura Chancay, Perú, red. Andrzej Krzanowski, Kraków: Uniwersytet Jagielloński, pp.19-35.

Krzanowski, Andrzej

2008 Kultura Chancay: środkowe wybrzeże Peru u schyłku epoki prekolumbijskiej (X-XVI w.), Kraków y Warszawa: Instytut Amerykanistyki i Studiów Polonijnych Uniwersytetu Jagiellońskiego, Polskie Towarzystwo Studiów Latynoamerykanistycznych.

Leyser, K. J

1965 “The Polemics of the Papal Revolution”, in Smalley, Beryl (ed.), Trends Makki, Fouad

in Medieval Political Thought, New York: Barnes \& Nobel, Inc, p. 53.

2004 "The Empire of Capital and the Remaking of Centre-periphery Relations", Third World Quarterly 25 (1).

Meyer, Lorenzo

1982 „La Revolución Mexicana y sus elecciones presidenciales: una inter-

Parsons, Talcott pretación (1911-1940)", Historia Mexicana 32(2).

1964) "Evolutionary Universals in Society", American Sociological Review 29 (3): 353.

Reid, Charles J.

2007 "The Rights of Children in Medieval Canon Law", Legal Studies Research Paper No. 07-34, Minnesota: University of St. Thomas School of Law.

Tierney, Brian

2008 Religion, law, and the growth of constitutional thought, 1150-1650, Cambridge: Cambridge University Press. 
Walling, Karl

1995 "Was Alexander Hamilton a Machiavellian Statesman?". The Review of Politics 57 (3).

Zaret, David

1996 "Petitions and the 'Invention' of Public Opinion in the English Revolution”, The American Journal of Sociology, Vol. 101 (6). 